\title{
Digital Materialities and Family Practices: The Gendered, Practical, Aesthetical and Technological Domestication of Play
}

\author{
Jessica Enevold \\ Department of Arts and Cultural Sciences, Lund University \\ jessica.enevold@kultur.lu.se
}

\section{INTRODUCTION}

Digital gameplay is now firmly embedded in everyday practices in many Scandinavian homes. This paper deals with the constitution of such practices by taking a closer look at the choreographing of the material objects essential to play and their role in the "design of everyday life" (Shove et al. 2007). Previous studies have looked at how players' gaming habits are tied up with time restrictions and time allowances that to a large extent are gendered (Enevold \& Hagström 2008; Enevold \& Hagström 2009). Here I turn to the domestic spaces of play, scrutinizing the home environment, in which the large part of today's playing of digital games takes place. Thus, instead of looking at how gaming ${ }^{1}$ is moving out of the bedrooms and into big LAN-landscapes (Taylor \& Witkowski 2010), this paper turns to the "domestication of play," and thus goes back inside the house, to see what it is doing to families and what families do with it. Domestication is understood as the process which makes play an everyday practice of the domestic realm and "bends" it to the wills and norms of the family. This article also investigates influence in the opposite direction: how play conditions domestic practices.

This paper is not about player motivation or how players game. Nor is it a theoretical ludotopic inquiry closely connected to game design (Waltz 2010; von Borries et al 2007). It shares some resemblance to Gidding's "microethnographic" work (2009) but is not focused on the 
gameplay "event." If I were to use the terminology in Gidding's study of the interrelation and co-constitution of gameplay with an emphasis on eradicating the distinction subject/object, perhaps this study would be an examination of the home-event, or possibly the family-event. As adamant as Gidding is about not separating screen/player or subject/ object, I am adamant about not separating play/home as co-constitutive of everyday life and the everyday practice and performance of family and home, gender and gaming.

Gidding's study brings to mind the application of Jon Dovey and Helen Kennedy's discussions of technicity (Dovey \& Kennedy 2006; Kennedy \& Dovey 2007), which emphasizes the connection between human subjectivity and technology. Here, although I still aspire to identify "relationships between technology, agency and aesthetics in everyday technoculture" (Giddings, 2009:149) this paper has both a narrower and broader material focus; on the one hand, it looks to game devices only, not specific games or gameplay, and traces their placement and trajectories around domestic space over time. On the other hand, this article pays attention to the design of the wider material setting of everyday family life -furniture, outlets, and interior decorating. Gaming is thus understood as merely one practice ${ }^{2}$ out of many depending on and affecting (or "colluding with" to use Giddings (2009) terminology ${ }^{3}$ ) other domestic materialities and practices. In short, using cultural analysis, ethnography, and practice theory whose theoretical origins and influences are explained below, I focus on material, not virtual, artifacts of gaming, specifically screens, consoles, and hand-held devices essential to play. I examine their locations and movements around the house, practices that "domesticate" play and influence playing practices and family performances. Domesticating digital materialities, gaming objects and, consequently, play, is integral to the design of everyday life. The empirical tales show how this takes place, and, in the process, a history of the domestication of play unfolds. 
Domestication as used here feeds into a body of work that deals with the adoption and appropriation of technology of households (see for example Silverstone, Hirsch \& Morley 1992; Silverstone \& Hirsch 1992; Lie \& Sörensen 1996; Silverstone \& Haddon 1996; Pantzar 1997). This article adds to this so-called "first wave" of domestication theory by investigating digital games as a key contemporary digital culture and information technology. In domestication theory, households are seen as significant economic and socio-cultural nodes of consumption and participation in the meaning making of media and information technology. This article does not propose a model for household domestication (see for example the four-phase model in Silverstone, Hirsch \& Morley 1992 or Mansell \& Silverstone 1996; or the domestication process as "a set of trials" in Lehtonen 2003), but provides cases from ethnographic field studies rather than a media or discourse analysis (see for example Routarinne 2005) of domestication. As in the above-mentioned theories of domestication, the end-users are in focus here. This article specifically underlines the role of these users by connecting domestication theory to practice theory, outlined in the following section.

\section{DESIGNING EVERYDAY LIFE \& PRACTICE THEORY}

The "stuff" (Miller 2009), the material consumer objects, that we surround ourselves with and relate to in our homes can be discerned as vital to many different everyday practices. I have chosen here the staging of the practices of play via material gaming objects and their relation to the practice of family, which in this paper are understood as mutually constitutive. To study domestic spaces and the commonplace arranging of objects means to align with social science and anthropological research interested in material culture and its role in shaping everyday life. The discussion of the significance of objects spoken of in terms of their agency pertains to a long-standing tradition of theorizing in which the issue has been to determine whether "structure" or "individual agents" or combinations thereof make up the fabric of the social. 
To the research efforts that attempt to explain social reality by combining structure and agents belong science and technology studies that center on the significance of artifacts (Latour 1992; Bijker \& Law 1992) and how such objects are integral to shaping "the socialness" of daily life (Latour 2000). Like Shove et al.'s (2007) and Miller's (2008; 2009) research of consumer culture, which also works in this vein, this paper goes one step beyond reading objects for their symbolic values and looks closer at the use of objects-here, in the sense of when and where certain objects of digital gaming are used-and its consequences for, and origin in, the dynamics of play and family. In doing so, norms can be found surrounding gender, gaming, and culture, to name a few, connected to the choreographing of game devices around a family's domestic space. These are also integral with designing everyday life and defined by aesthetical, practical and technological conditions and choices.

In this paper I use what is often termed a new wave of practice theory (Schatzki, Knorr-Cetina \& Savigny 2001). It is a tradition of practice theory that synthesizes its many origins and often is used in consumer research (see Shove 2003; Warde 2005; Shove et al. 2007; Miller 2009) to analyze the meaning of objects in relation to the design of everyday life (Shove et al. 2007). This moves somewhat away from analyzing the discursive aspect of playing digital games and more firmly into the "doing" of it. However, I reiterate, the focus is not a phenomenological interest in smell, feel and texture of objects (Pink 2009), but their significance and meaning in home-making, family-making and related activities.

Shove et al. (2007) combine the emphasis made in Latour's work on non-human actors with that of practice theory, which in Reckwitz' work centers on such concepts as "bodily movements, things, practical knowledge, and routine" (Reckwitz 2002). Practice theory originates from the 1970s and has developed by aid of several thinkers over the 
years, with Sherry Ortner making a notable contribution to the field of anthropology 1984). Practice theory as articulated here is influenced by Ortner (1984) and has its roots in Pierre Bourdieu's work (1977) focusing on the importance of architectural forms for human action, Giddens' (1984) theories of structuration and Judith Butler's philosophical deconstructions of gender (1990). Butler's theory of gender performance is deeply anchored in the lived experience and appearance of the body in daily life. Here, the focus is not so much on the anthropology of the body as on the artifact used by players, whose bodily movements are influenced by the nature, mobility and movability of their playing devices, and what they reveal about family life (Miller 2001). Yet naturally, as the case studies below will illustrate, the architecture of domestic space figures into the staging of domestic life and the body. The body is the human vehicle which acts out the play, the work, the listening, etc. It is obviously vital to the understanding of human behavior, culture and social action from an everyday perspective.

\section{RESEARCH METHODS AND EMPIRICAL BASIS}

This paper originates from the research project "Gaming Moms" that I have run together with my colleague Charlotte Hagström at Lund University for approximately five years (2008-2013). The fully expanded aims and scope of the project can be found on the project's research blog (Enevold \& Hagström 2008b). To briefly summarize: the main aim of that project has been to nuance stereotypical notions of gamers and gaming. The project has included approximately 75 informants in total. The material has been gathered using a variety of tools: discourse analysis, an online-questionnaire and a mix of qualitative netnographic and ethnographic methods: e-mail questionnaires, semi-structured face-to-face-interviews in the informants' homes, player diaries, photographic documentation of game spaces and auto-ethnography.

The project has used both an emic perspective, that is focusing on what 
the studied players name as significant and an etic perspective, which is the focus of the researchers as observers and the terminology they use for analyzing the observed. Auto-ethnographically collected material is viewed and used as researcher-reconstructed data (Strathern 1987) rather than text used to create a fiction-style auto-anthropology (Ellis 2004).

In the highlighted cases used below, which have been extracted from the approximately 15 that allowed access to the informant's home, the initial and main focus was on the mother's position, doings, practices, utterances etc., but, as the research progressed and developed, the empirical collection naturally came to include material also on other family members. However, fathers figuring in the narratives below were not systematically consulted for information. It should also be noted that in some families, fathers did not play computer games at all - this is as a rule stated in the case narratives accounted for below. But their presence and opinions obviously played a large part in the family dynamics and everyday practices. Their views and activities are nevertheless mainly gathered through observation - listening in and participating in the daily life of families - and only sporadically through ad-hoc interviews and sometimes through informal conversations. For the overall analysis, the case narratives reported here are combined with empirical findings from the large project, whose methods are accounted for in the first paragraph of this section. All informants have consented to the information being used in an academic context.

I should hasten to add that the analysis presented in this article emerged as the research project developed in exciting and unanticipated ways. The original research questions included inquiries into the everyday practices of adult women gamers and potential time and activity conflicts they experienced in their everyday life with their immediate surroundings - family, work, and other factors or persons directly or indirectly connected to their gaming. Although somewhat 
different in scope from the original research project, this analysis stays within the same realm of investigation: the everyday practices of gaming paying specific attention to gender and family issues, which makes it possible to generate conclusions about the constitution of not only the contemporary gamer but of gaming as a domestic technology, its history and its factoring into the equation of equality, work and leisure in everyday life in today's Western society.

\section{DOMESTICATING PLAY \\ Domestic space-time ordering}

In constructing the scenography of the home, deciding where items should be placed (or not placed), and moving objects from one room to the next, play is staged and simultaneously the family. Play is in the process domesticated in the double sense of the word - brought into the home, but also subordinated and subjected to the norms of the family and the home. Studying the artifacts of play, it is clear how playing practices are being performed more or less consciously; gametime and game-space are bounded (at least temporarily) by seemingly routine movements around the house. The case material has generally demonstrated relatively undramatic family scenes. Far-reaching surveillance and forceful disciplinary actions have been infrequent. As a rule, gaming is regulated through less overt tactics. Rather, game space and time seem to be regulated in an automatic and routinized way and motivated, or ruled, by a range of norms, explicit and implicit, which I will go through below. Of course, both covert manipulation and open surveillance do occur. Certain families do try to create a "reverse" panopticon situation (Foucault 1979) by placing computers centrally, but these situations seem short-lived and are quickly abolished as children grow older and insist on their own gamespace. Families Four and Five, presented below, as well as Family Twelve (which is not presented below but consists of a family of one mother and a child of thirteen), serve as good examples of limited surveillance practices. Most family cases and their everyday family and gaming rules and per- 
formances are better explained using a model employed by Shove et al. (2007) engaging a form of practice theory that strives to account both for individual agency and social norms in the construction of social reality. This inclusive theorization of practice resonates better with the way the co-constitution of play and domestic space is carried out in a process involving family members as well as gaming materialities.

\section{Rooms and Regulating Norms}

Families organize their homes around objects for many reasons; some are explicitly stated as being practical, others as aesthetical or technological. The home is constructed through a number of practices such as sleeping, eating and playing, which are hierarchically evaluated in relation to subject positioning as well as object positioning. An example is that of the domestic space that exists in most homes. All examples in the study are from white European, middle-aged, upper middle-class families. The domestic order mainly discussed here depends upon its construction at this particular intersection of wealth, class, ethnicity, nationality, (dis)ability and age. I want to acknowledge that it thus represents a limited privileged segment of Scandinavian households.

Five people live in the household of Family Five, three children and two adults. All children are under the age of eighteen. In most homes, there is a domestic space called a bedroom. Bedrooms are in the average Scandinavian family with children who can be found in the project- material, and the example of Family Five, a space primarily intended for Sleep, Work, and Play, in that hierarchical order. Eating is completely ruled out. ${ }^{4}$ In Family Five's bedroom is placed a double bed, a closet, a bookcase and a corner table with a "good" stationary computer, that is, a fairly new computer with a graphics card, processor and internal memory optimized for gaming.

Family Four has four members. The two children, both under eighteen, each have a computer in their rooms. The mother has a comput- 
er in the parents' bedroom and the father has a computer in the living room. The activities in the parents' bedroom are here ordered along similar lines as Family Five, although Sleep here gets more competition, since this bedroom compared to that of Family Five is quite small. In Family Four, the parents' bedroom is also the main office of the mother who mainly works from home.

In Family Five, there is only one more and older computer of inferior quality placed in another room. Family Five abides by a number of norms that are both implicit and explicit as to what type of activity can go on in the bedroom, in this case the parents' bedroom, but this basically also goes for the children's bedroom at this moment in time. These activities are ranked according to a system of unwritten rules. They work according to norms about domestic activities that look more or less like this:

Sleep. Sleep is ranked highest among all activities: whoever wants to sleep has prioritized access to the bedroom. It is the activity that more or less without question is allowed the most amount of hours in a 24hour cycle of everyday life. Sleep does not need to compete with any other activities and is considered a healthy and useful activity. If somebody, the husband or wife, or any of the children, wants to work or play on the computer, this is frowned upon by the person who wants to sleep, and if the disapproving person wins out in the conflict, play is either excluded or relegated to somewhere else. There is, as said, at this moment in time one more computer in the home, which is possible to occupy. However with five people in the household, that computer is often taken. If the person who chooses sleep does not get her/his way, the person who takes a seat at the computer in the bedroom often plays/works with a bad conscience. To take into account individual characteristics, the father in this family is hard of hearing and is not as easily disturbed as the mother. Still he is less interested in computers and does not play computer games himself, thus dislikes activities 
on the computer more than the mother does. She sleeps less heavily, but she is also more generous with allowing one of the children a late night chat with friends or a quick check into their online game before bedtime after homework is completed on the bedroom computer when the other siblings occupy the computer in the other room. Being a gamer herself she has a different attitude to the computer both as technology for work and for play.

Family Four experiences more friction when it comes to occupying the bedroom space. The father in this family is a very light sleeper and wants nobody else in the room while he sleeps, whereas this is allowed in Family Five. The size of the room also makes it very warm and stuffy, which allows for less comfort when it is time to go to bed. Since play often takes place late at night after work is done and a family meal has been prepared and eaten, the heat-producing activity of the hardware is at its height in the evening when bedtime draws close.

Work. The underlying norm operating regarding work, in both families, is that it should preferably be carried out in an office or wherever the job is primarily physically located. If somebody chooses to work in the bedroom, that person must accept being disturbed. Work time is conditional and time-limited. It is of course important to note here that the view of work and of work time differs greatly between different professions, age groups and social classes to name a few possible factors of influence. People who work strict eight-hour days between approximately $8 \mathrm{am}$ and $5 \mathrm{pm}$ may differ vastly in their opinions from certain groups of professionals who make little distinction between work time and leisure time. A lot of research has been done on the relationship between work and "free" time (e.g. Nippert-Eng 1996; Brannen 2005), and the relation of this blurring of boundaries to the separation of time-space in postmodernity (Harvey 1989). In Family Five and Family Four, the fathers both have office-bound occupations and schedules, whereas the mothers often work from home or fre- 
quently bring work home. They consequently end up blending traditional work and playtimes to a much greater extent than the fathers or the children.

Play. In both families play should usually be done when everyone else plays, or when there is no work left to do - school work, house work, maintenance, taking out the trash, shopping. Homework and work that is brought home should similarly be finished before play is allowed. If somebody plays outside of communal times, rule number one that stipulates sleep's prioritized position is brought into effect. In relation to the children, their age and lower position of authority and power are used to regulate their playtime. Those who want to play outside of sanctioned playtimes are in Family Four verbally warned off or reprimanded. This goes for both adults and children. Play practices are also in both families, although in different ways, regulated by the classical "gender-power system" (Hirdman 1988, building on Scott 1986).

Gender. The dominant gender system is usually that which dictates that the mother or woman in the domestic sphere be the one to make sure that there is food in the house and/or is the one who should keep an eye on what the children are doing. This is a norm that overrules most other norms and is the superior and silent principle that overrides many other norms in a majority of the families that this project studied.

In Family Four, food responsibilities as a rule fall on the mother. Food preparation is explicitly stated as prioritized before all other activities, specifically play. If the mother in Family Four is not seen (in view) for what is perceived as too long a time period or the rest of the family is hungry, this norm is automatically called into effect. The rest of the family members do not make dinner, but encourage the mother to stop her playing or working to prepare food, if she has not already 
done so. Working late is in this case a complicated situation, since work in effect is in the home and not spatially separated from the time and space of family or play. The gender-power system generally impacts relations also between brothers and sisters in families, as many other studies into the distribution of gaming and technology have shown (for example Schott \& Horrell 2000; Kerr 2003; Crawford $\&$ Gosling 2005; Dixon \& Bodreau 2009). However, in the cases reported below, the family constitutions were such that no conclusive material can be presented here that might show how children acted or came into gaming differently from their siblings due to their gender. Data was not collected such that detailed information can be given on gendered negotiations between parents and children. This would have required considerably more research and a different research focus, but is a question well worth pursuing in future studies or follow-up visits.

Family. All of the norms and practices that are taking place in domestic space and time constitute what become naturalized ideas of what it means to be a family and what play and work are in contrast to the family and to each other and to other activities. Joint activities are favored or implicitly ranked higher in both Family Five and Family Four. For example, family meals are prioritized before individual snacks and non-play activities are rewarded - if the children go outside or read or help with housework this is highly praised. If they or any of the adults perform work on the house, repair, clean or vacuum, this behavior is commended and further strengthens the position of work vis-à-vis play and the family vis-à-vis individuality.

To further illustrate the significance of the gaming devices, their number, type and location, I will give further examples from the perspective of owning, possessing and placing game artifacts as well as how the design of the everyday life and playspace changes over the lifetime of the family hand-in-hand with technological development and acquisitions. 


\section{Staging - Scenographies of Play, Gender and Family}

When I first meet Family Five, they have two computers. One is placed in the parents' bedroom, the other in the youngest child's bedroom. The youngest often sleeps in the parents' room, which makes that child's bedroom a rather open and public room. At the same time, the parents' bedroom is also "open" to the children; they are allowed in at almost any time of the day, except when both parents are asleep. The out-dated, "bad," computer is placed in the youngest child's bedroom room and the more current, "good" one (which is what they call it) in the parents' bedroom. This is done out of fairness; no child should have more access to computers than any other. At the same time, the parents can exercise control over and oversee the children's computer activities. Both computers are set up with the screens turned out into the room. The "good" computer has a set of speakers. Earphones can be plugged into this computer as well, but these earphones tend to "disappear" and cannot always be located, which means that sometimes there is sound coming from this computer. By setting the screens up this way, the parents keep an eye on what the children do and distribute the time evenly between the children and between their homework/play activities. Fighting over game time is not allowed.

The above-described arrangement is an ordering of space that is practical in terms of parenting and teaching siblings to share. However, sometimes the placement of gaming devices is done for less practical reasons. It should be added that the "good" computer is primarily bought for the purpose of supplying Family Five with a good PC for online gaming. But, why then is the machine not placed in the hallway, which is an open space between the bathroom and the kitchen, where there is room for it? It is an even more "public" space that all members of the family share and that the parents spend more time in and have more overview of than the bedroom that they mainly use to sleep in. After all, does not sleep come before play? 
Sometimes domestic space is organized due to limitations of square footage or family size. In Family Five, each child has its own room, so space is not an issue. The reason for not purchasing more computers is mainly that of keeping track of gametime and the idea that more computers than three would be excessive. There is an open space in the hallway mentioned above, but the father of the family has rejected it on aesthetic grounds. At this point in time, there is no wireless internet connection in the home. The two existing computers are connected to a modem through cables. The official owners of these computers are the parents. The children do not have computers of their own.

The two computers are placed very close to the cable outlet on the wall; a hole has been drilled through the wall to avoid having a long cable pass through two rooms; "it looks terrible" claims the father. He is meticulous about hiding wires and cables and would have built the electrical system and cables inside all walls if he had constructed the house himself. He has now managed to keep the cable length to a minimum. Had one of the PCs been placed in the kitchen, the cable situation would have been unacceptable. He also finds the PCs with their big screens hideous and unwieldy. In addition to the idea of a shared computer and avoiding excess gametime, aesthetics thus plays a major part in designing the domestic space and consequently everyday life practices such as play and homework. Actually it even precedes the idea of control and other practical functions. It is also obvious that the cable installation dictates which two rooms get to house the computers - in this case, the architectural plan, the material conditions of the wall construction, the outlets and technological conditions of wiring. Moreover, the internet provision through cable to the computers rather than a wireless connection in the home forces the family to stage their domestic practices around it. Decisions about where play should be carried out - what table, what room, what type of device thus depends on much more than individual choices. The architectural conditions and aesthetic preferences regulate play by excluding 
other bedrooms (inhabited by the other children) or living room, kitchen and hallway, from being playspaces. Of course, accepted play preferences and habits also dictate that internet access be acquired in the first place and that a "good" PC be purchased. These in turn were domesticated by the aesthetical, technological and practical conditions and resulting stagings of the home and family.

Another example of the co-constitution of spatial arrangements, family and play practices comes from Family Six. Once a family of six, this family constellation now consists of two adults and one child. Family Six has built a game room for the entire family, which contains three stationary PCs. They have space to do this since they live in a huge four-story house. Since both parents are avid players, they both feel their gaming has affected their children. Their ideal of what it means to "do family" is discordant with extensive play practices. When their playing was at its peak - timewise - and all children lived at home, the mother still had most of the responsibility for food preparation, which caused conflict between the husband and wife and between them and the children. They used to play World of Warcraft (Blizzard 2004) and were both intent on acquiring certain sets of gear through playing matches in so-called Battlegrounds, which generated credits that could be turned in for valuable items. At the time this was a popular activity that required signing up for a battle and then queuing, sometimes for up to 20 minutes, to play. If you were not physically at the computer to accept your invitation to join a battle once it was extended to the player by the system, you lost your place in line. This was cause for upset in this family, (the kitchen stove was rather far from the PC) and the mother tells me that in retrospect it felt rather crazy, but completely motivated and justified at the time. In order not to neglect the family but still achieve the goal of the game she had set, they worked out a system where they took turns watching the computer and she was running back and forth to the kitchen to check on the food. Building the game room they retained some of the traditional collective practice 
of family, by co-locating in domestic time-space. This mother plays with and talks to her fellow-players wearing her headgear with one of the ears uncovered, so she can talk to, and hear, her husband and her youngest child, who also has a computer in the game room, simultaneously. As can be observed here and in other examples, audio also plays a significant role in the process of domesticating gameplay and performing gender and family. Domesticating play, designing their space, arranging their digital materialities, they have revised both their notion of what play and doing family means.

\section{Choreographing domestic time-space}

As Family Five has grown older, their domestic gaming landscape has gradually changed. When I visited again four years later, they are not only four years older, which is significant not the least in the case of the children regarding the increased responsibility and abilities they are supposed to have in relation to games and gaming (according to their parents), the passing of time has also affected the parents who I understand have lived through a cultural adjustment to the presence of both gameplay and screens as everyday devices that they now take more for granted. The past four years their home-gaming devices have shifted places, some have been replaced and new ones have been acquired. There are more screens, consoles, loudspeakers, earphones and related devices present all over the home.

One reason why time spent on computer gaming, but also on other activities performed on personal computers, is often regarded as negative by general opinion and portrayals in media is that it appears to exclude those around the player. The person in question plays or talks with somebody that cannot be seen or felt by anybody else but the person at the computer. This exclusion, or audio-visual distancing, is in both Family Five and Family Four perceived as more "serious" if the person and/or the screen is not within sight. In Family Five all screens were previously turned out towards the room. Now, they are all turned 
away from the door opening as gaming has become more privatized and individual. On the other hand, it has also become more collective. I return to discuss this in more detail below.

In Family Four, where the conflict over play/work time was more tangible, the screens were in the parents' cases early on turned away from public eyes. Nobody wanted to be monitored by the other since the tolerance for play had been reduced as the appeal to family values of collectivity had been strongly voiced. It is essential to note here that work cannot be negotiated to the same extent as play - work has a very strong position versus play, as was indicated above. This resulted in both parents keeping their screen activities to themselves in a move to retain control over their time spent at the computers. If dinner needed to be fixed, this could wait a moment longer in the case of work, but not in the case of play. Play must in both Family Five and Family Four cede to joint activities like film watching or food-consumption. The practice and performance of family thus outweigh the practice of play in both cases. As a result, the distinction between play and work in some instances are intentionally blurred. To mention a related example: in Family Eight (a family of three), a mother sometimes goes down to check on the washing machine, but this is also the place she keeps her laptop and she thus plays a couple of rounds of a short game online while she is down in the basement. In my interpretation she still prefers to label this activity "work" since work strongly supports the assumed ideal of mother and of family - she avoids potential conflicts with norms underpinning the family. A mother out of sight is as a rule not a good thing (see for example Enevold \& Hagström 2008; 2009).

The advent of mobile computers in all shapes has radicalized the spatial and temporal ordering of both family and play practices. The mobilizing qualities of the laptop now neutralize the negativity of gameplay as well as work that takes place out of sight. The father in 
Family Five has now purchased a laptop of his own. The parents now pay bills together taking the laptop with them to the living room. In Family Two, which is a family of three who used to be seven, in which the mother previously felt the tension that would arise when she left the living room to play some of her games late at night, is now able to sit next to her husband, who eventually also has obtained a laptop. They use the laptops for different purposes - he watches TED-talks and nature films and reads the family blog that one of the children has set up. She watches movies, plays games and emails and does a lot of work-related writing on hers. But, they do this in silent togetherness (both use earphones so as not to disturb the other) and the husband is reportedly quite pleased with this change. They maintain the sense of, the practice of, family and collectivity in the face of, and thanks to, technological change.

A very important factor is that Family Five as well as the other families described now all have wireless internet access. In Family Five's living room there is now also a big flat-screen TV, an Xbox and a Wii. The Wii has four remote controllers (practical ordering) neatly placed in a rack inside a cabinet (aesthetic ordering). Some play practices have thus been moved from the PC out of the bedroom into another public family space. The mother has also obtained a laptop. This means that TV-watching, gameplay and work now at times take place simultaneously in the living room, similar to Family Two. Play is domesticated, but play-devices also domesticate the players, the family. It draws social action, play, through cultural material objects like games, to specific spaces. The new flatscreen and the introduction of the Xbox brought more family members into the living room, not only to games but also to DVD-watching. At the same time their new game artifacts dispersed them. At the end of the four years, each child also got a screen of their own: the youngest started playing games on an iPod, the other two got their own PCs in their rooms. The parents bought a laptop each. The majority of the family could now move around 
independently. Eventually the youngest child in Family Five also got a stationary computer and a private TV and the Xbox was moved into that child's bedroom. I noticed on subsequent visits that I saw the children less often - they were cooped up, as it were, in their rooms. On the other hand as the Wii and Xbox first entered the home, they had occupied the living room and the TV in bigger groups, playing loudly with friends.

Evidently, teenagers often want to be by themselves, and Family Five adapted and decorated accordingly. For a short period of time a long cable was (under protest from the design-sensitive father) drawn from the router in the main access room through a number of other rooms to the room of the oldest child, who was the first to insist on a private computer. As soon as possible this cable was removed and replaced by a wireless internet connection. The mobilization, or choreographies of play and family in Family Five did not stop with wireless internet and individual computers. Smartphones arrived and added supplementary options for gameplay, emailing and listening to music as well as almost endless relocation options for their human bodies in relation to the technical medium needed for the chosen activity. Playing a game in front of the television while together with others became inconspicuous and almost passed under the radar for acceptable family-room activities.

Of course, the type of games that can be played on a smartphone is limited, and big online-games still require specific technological objects to be played. Adding vocal conversations over software like Teamspeak, Ventrilo or Skype into the equation, the practice of playing in teams or with others over the internet require the privacy of the bedroom in order not to disturb others' play, work or TV-watching. Both music and talk are transmitted over such auditory channels, that is, the gaming child does not only play music locally, listening to Spotify or private collections, but may also take part of other players' 
auditory output, for example, conversations, sound effects, and music. This, in turn, contributes to keeping certain types of games on the lower rungs of the ladder of activities allowed in the home, since they are both more audible and noticeable. Despite this, the big threat of gaming to "performing family" seems more or less reduced to manageable size. As the parents adopted the new technologies and familiarized themselves with them, they also felt more in control of what their children were doing without them. In Family Seven, a family of four, the event of the iPad brought one of the parents who had previously played extensively in the bedroom, into the living room, a move which significantly reduced the amount of stress expressed by the other partner who thus were able to co-locate in a sense similar to Family Two. In Family Five, mobilized gaming devices also reintroduced play into the parental bedroom by way of the mother's laptop on which she played games sitting on the bed after having dinner with the family, a procedure which is still a non-negotiable practice in most studied families.

As a final illustration, I offer you a tale from the socio-cultural field of my own family. As we - my mother, my son and I - sit down to hang out in front of the TV, and as most other families in this study, we have just finished a shared family meal, my mother, formerly not very keen on the rest of the family's penchant for gaming, hauls out her newly purchased iPad. She immediately has to work hard to gain sovereign control over her Wordfeud ${ }^{5}$ game (hbware 2010) ferociously fighting off my game-hungry son who wants to help her place the tiles. Although I suspect my mother's interest might wane with time, our conversations have been considerably reduced because of her new friend the iPad and her new love: the game. Our family performance has indeed altered with the advent of new material gaming objects. I look at the two of them on the other side of the coffee table. Nobody wants to talk to me and nobody wants to watch the program with me. What do I do? As a gamer and child of the times, I pull out my iPhone and roll out another word. 


\section{Conclusion}

To conclude, in this article I have examined a number of families' implicit and explicit stagings of play, but also of family and gender. It demonstrates how integral everyday practices, seemingly mundane scenographies and choreographies - practical, aesthetic and technological ordering of domestic space-time and game artifacts, are to producing and conditioning everyday performances of gender, family and gaming. It shows how play is domesticated - subordinated and subjected to the norms of the family and the home, and vice versa, how play conditions the domestic. The empirical tales show a change over time in everyday practices that make up the design of everyday life from the perspective of digital gaming materialities. In the process, a history of the domestication of play can be discerned.

The physical presence of bodies and screens, visuals and sounds, in the same space reduces the threat of the unknown, the unseen and the unheard. The increased mobilization of gaming devices changes communication and interaction patterns in families (who can afford to acquire them). Over time, family members-parents and children-are habituated to new cultural practices and technological artifacts and the resulting subject-technology relation, or technicity (Dovey \& Kennedy 2007), is part and parcel of their everyday practices. Everyday practices depend on an "ensemble of procedures ... schemas of operations and of technical manipulations" (de Certeau 1988:45). Technicity, whether situated by the terminology of Bourdieu's "habitus" or Foucault's "ideology" as de Certeau phrases it (1988:45) is integral with the conditioning of everyday practices. Everyday practices are without doubt, whether reflective (Giddens 1979) or results of less reflective habituation (Bourdieu 1977) ideological and produce in daily doings, routines etc, socio-cultural categories such as gender and class. Here, everyday practices are seen to produce ideas of gender, play and above all the nuclear bourgeois family. They enforce, but they also renew and alter, ideas of how family should be performed and how it should 
move and stage itself and the material objects upon which it depends in domestic space. The design of everyday life and digital materialities, domesticates play and, in turn, play (re)constitutes family practices.

\section{Acknowledgements}

I thank the four anonymous reviewers and the editors, among them Raine Koskimaa, for their insightful comments, which I have incorporated in the text as far as possible. They made it a delight and very easy to improve this text before its final publication. I also want to acknowledge my great colleague and friend Charlotte Hagström and the work we have done together the past five years within the "Gaming Moms" project. Without it there would not have been a wealth of material or inspiring discussions to draw from and build presentations and articles upon, including this one. I thank her deeply for our fun, creative and rewarding professional collaboration. Finally, I want to direct my appreciation to all the families that have offered access to their personal tales and private spheres and thus made this research possible.

\section{Endnotes}

${ }^{1}$ I make in this paper no distinction between playing and gaming. This is part of my professional mission and a discursive tactic rather than an omission. Strategically, gaming and playing need to be viewed on equal terms as gaming and playing come encumbered with ideological notions that have political significance, specifically within the context of making game culture evenly distributed between different gaming subject positions (Enevold 2009; 2011).

${ }^{2}$ One could perhaps speak of gaming practices as several events, but the philosophical discussion of what constitutes events is quite large, complicated and much too space-consuming to be brought up here.

${ }^{3}$ The collusion term, although metaphorically appealing, may nevertheless be best suited to understanding gameplay events, not the least 
because of its etymology.

${ }^{4}$ For the sake of simplicity I leave amorous interactions aside, since this is a practice that has a discourse of geography and morality all its own and is just too complicated to enter into this discussion.

${ }^{5}$ Wordfeud is a wordgame for smartphones and the iPad that basically is a copy of Scrabble but for only two people.

\section{BIBLIOGRAPHY}

Blizzard Entertainment World of Warcraft [PC Computer, Online Game] Blizzard Entertainment. Irvine, CA, USA, 2004.

Enevold, J. "Mama Ludens Goes All In: Gaming Mothers, Fun and the Ludic Revolution.” Presentation. Playful Experience Conference at Tampere University, Finland. 2-3 April 2009.

Enevold, J. "Mama Ludens vs Fanboi - What is Wrong with the Gaming Revolution?" Invited Lecture at The Center for Games and Playable Media, University of California at Santa Cruz, USA. 16 May 2011.

Enevold, J. and C. Hagström. "My Momma Shoots Better Than You! Who is the Female Gamer?" In Proceedings of the [Player] Conference. Copenhagen. 26-29 August 2008. ISBN: 978-877949-182-3

Enevold, J. and C. Hagström. "Gaming Moms: Time, Play and Everyday Life -Research Blog.” 2008b. http://gamingmoms.wordpress. com/

Enevold, J and C. Hagström. Ethnology Meets Game Studies. Ethnologia Scandinavica vol 39: 27-41. 2009. ISSN 0348-9698.

Crawford, G. and V. Gosling. “Toys for Boys?' Women's Marginalization and Participation As Digital Gamers." In Sociological Research Online vol.10 no. 1. (2005). http://www.socresonline. org.uk/10/1/crawford.html 
Dove, J. and Kennedy, H.W. Game Cultures. Games as New Media. Berkshire, U.K.: Open University Press, 2006.

Dixon, S. and K. Boudreau. "Breaking New Ground: Innovation in Games, Play, Practice and Theory." In Proceedings of the DiGRA Conference, London: Brunel University (2009). http://www. digra.org/dl/db/09291.10561.pdf

Bijker, W. and J. Law. (Eds.) Shaping Technology/Building Society: Studies in Sociotechnical Change. Cambridge, MA: MIT Press, 1992.

Borries, F.V., S. P. Walz, M. Bottger, D. Davidson, H. Kelley and J. Kücklich. (Eds.) Space Time Play: Computer Games, Architecture and Urbanism: The Next Level. Basel: Birkhauser, 2009.

Bourdieu, P. Outline of a Theory of Practice. Cambridge, U.K.: Cambridge Univ. Press, 1977.

Brannen, J. "Time and the Negotiation of Work-Family Boundaries: Autonomy or Illusion.” In Time \& Society vol. 14 no. 1 (2002): 113-131. DOI: 10.1177/0961463X05050299

Butler, J. Gender Trouble: Feminism and the Subversion of Identity. New York, NY: Routledge, 1990.

de Certeau, M. The Practice of Everyday Life. Berkeley, CA: UC Press, 1988.

Ellis, C. The Ethnographic I: a Methodological Novel about Autoethnography. Walnut Creek, CA: AltaMira Press, 2004.

Foucault, M. Discipline and Punish: the Birth of the Prison. New York, NY: Vintage Books, 1979.

Giddens. A. Central Problems in Social Theory: Action, Structure and Contradiction in Social Analysis, Berkeley, CA: University of California Press, 1979.

Giddings, S. "Events and Collusions: A Glossary for the Microethnography of Video Game Play." In Games and Culture vol. 4 no. 2 (2009): 144-157.

Harvey, D. The Condition of Postmodernity. Cambridge, U.K.: Blackwell, 1989.

Hbwares. Wordfeud. [iPad; iPhone], 2010. 
Hirdman, Y. Genussystemet: Teoretiska Funderingar Kring Kvinnors Sociala Underordning. Uppsala: Maktutredningen, 1988.

Kennedy, H W. and J. Dovey. "Technicity: Power and Difference in Game Cultures."

In: Keynote: GameInAction. 13-15 June 2007, Goteborg, Sweden. http://eprints.uwe.ac.uk/93/ Accessed 2012-02-19.

Kerr A. "Women Just Want to Have Fun - a Study of Adult Female Players of Digital Games." In Proceedings of Level Up: DIGRA Conference. Utrecht: University of Utrecht, 2003. http://www. digra.org/dl/db/05163.29339.pdf

Latour, B. "Where Are the Missing Masses? A Sociology of a Few Mundane Artifacts." In W. Bijker and J. Law (eds) Shaping Technology/Building Society: Studies in Sociotechnical Change, pp. 225-58. Cambridge, MA: MIT Press, 1992.

Latour, B. "When Things Strike Back: A Possible Contribution of 'Science Studies' to the Social Sciences." In British Journal of Sociology vol. 51 no. 1(2000): 107-23.

Lehtonen T. "The Domestication of New Technologies as a Set of Trials." In Journal of Consumer Culture No. 3 (2003): 363-385.

Lie, M, and K. Sørensen (Eds.). Making Technology Our Own? Domesticating Technology into Everyday Life. Oslo, Norway: Scandinavian University Press, 1996.

Miller, D. (ed.) Home Possessions: Material Culture Behind Closed

Doors. Oxford, U.K.: Berg, 2001.

Miller, D. The Comfort of Things. Malden, MA: Polity, 2008.

Miller, D. Stuff. Cambridge, U.K.: Polity Press, 2009.

Nippert-Eng, C. Home and Work: Negotiating Boundaries through

Everyday Life. Chicago, IL: University of Chicago Press, 1996.

Ortner, S.B. (1984) "Theory in Anthropology Since the Sixties." In

Comparative Studies in Society and History, Vol. 26 No. 1 (1084): 126-166.

Pantzar, M. "Domestication of Everyday Life Technology." In Design Issues. vol. 13 no. 3 (1997): 52-65. 
Pink, S. Doing Sensory Ethnography. Los Angeles,CA: Sage, 2009.

Reckwitz, A. (2002) "Toward a Theory of Social Practices: A Development in Culturalist Theorizing." In European Journal of Social Theory. vol. 5 (2002): 243-263. DOI:10.1177/ 1368431022222543.

Routarinne, S. "Domestication and Context: Studying Objectification in Print Media." Nordic Design Research, 2005. http://ocs.sfu.ca/nordes/index.php/nordes/2005/paper/view/119

Schatzki, T R., K. Knorr-Cetina \& E. von Savigny (eds) The Practice Turn in Contemporary Theory. New York: Routledge, 2001.

Scott, J. W. "Gender: A Useful Category of Historical Analysis." In American Historical Review vol. 91 no. 5 (1986): 1053-1075.

Schott, G.R. and K.R. Horrell. "Girl Gamers and Their Relationship with the Gaming Culture." In Convergence no. 6 (2000): 36-53.

Shove, E. Comfort, Cleanliness and Convenience. The Social Organization of Normality. Oxford / New York: Berg, 2003.

Shove, E., M. Watson, M. Hand, and J. Ingram. The Design of Everyday Life. New York, NY: Berg, 2007.

Siverstone, R., and L. Haddon. "Design and the Domestication of Information and Communication Technologies: Technical Change and Everyday life." In R.E Mansell and R. Silverstone (eds.) Communication by Design: The Politics of Information and Communication Technologies. Oxford, UK: Oxford UP, 1996.

Silverstone, R., Hirsch, E. \& Morley, D. "Information and Communication Technologies and the Moral Economy of the Household." In R. Silverstone and E. Hirsch (eds) Consuming Technologies. Media and Information in Domestic Space, 1992.

Silverstone, R. and E. Hirsch. (eds.) Consuming Technologies. Media and Information in Domestic Space, London, U.K.: Routledge, 1992.

Mansell, R. E. and R. Silverstone. (eds.) Communication by Design: the Politics of Information and Communication Technologies. Oxford, U.K.: Oxford University Press, 1996. 
Strathern, M. "An Awkward Relationship: the Case of Feminism and Anthropology." In Signs Vol.12 No 2 (1987): 276-292.

Taylor, T. L. and E. Witkowski. "This Is How We Play It: What a Mega-LAN Can Teach Us about Games." In Proceedings of the Fifth International Conference on the Foundations of Digital Games (FDG '10). ACM, New York, NY, USA, 2010, p. 195-202. DOI=10.1145/1822348.1822374 http://doi.acm.org.ludwig. lub.lu.se/10.1145/1822348.1822374.

Walz, S.W. Toward a Ludic Architecture: The Space of Play and Games. ECT Press, 2010. http:// repository.cmu.edu/ectpress/5 Warde, A. "Consumption and Theories of Practice", in Journal of Consumer Culture vol. 5 (2005): 131-53. 